\title{
Economic Model of a Whole Hospital Picture Archiving and Communication System Installation
}

\author{
H. I. Glass
}

$\mathbf{T}$ HE model used in this study was developed from the work of Saarinen et al, but some simplifications have been introduced. The basis of the model is to estimate the recurrent and capital equipment costs in a hospital using a conventional radiography department and to compare the costs of only those elements that differ from the corresponding requirements for a hospital utilizing a picture archiving and communications system (PACS) installation. The estimated difference between the direct and indirect costs and savings and the net present value (NPV) of going "filmless" is calculated. The model sets out a wide range of assumptions relating to such factors as changes in maintenance costs, labor costs, opportunity costs, and capital acquisition costs and builds in the various relationships between the assumptions that will affect the operational cost of the radiography department and hospital.

The model involves a detailed examination of the possible effects of installation of PACS on the operational pattern of a 480 -acute bed British hospital. The changes required in the operational pattern of the hospital could provide indirect benefits which are a vital element in the economic justification of installing a PACS.

\section{GENERAL DESCRIPTION}

The model has six discrete direct cost/saving components. They relate to the cost of archive material and film use, labor, maintenance, operation and supplies, space, and capital (equipment and building). Seven indirect saving components are also included in the model, representing opportunities for savings that would have to be developed and transformed into real savings by introduction of administrative and operational changes in the hospital. These indirect benefits relate to saving of junior medical staff time, reduction in unnecessary investigations, savings in radiologist, radiographer, and clinician time, redesignation and change of use of a number of acute (high cost) beds, and reduction in the length of stay of inpatients.

Where possible, precise estimates have been included in the model. The indirect savings es- timates would have to be achieved by cooperation between management and clinicians. No account has been taken of the potential increase in income generation capacity created by the improved availability of time on the part of the radiologists, radiographers, and clinicians. The potential savings have been derived from a percentage of the salaries only, corresponding to the estimated improvement in their efficiency, and this has been included in estimating the benefit.

\section{HOSPITAL AND "DEPARTMENT-ONLY" PACS}

The model has been used to analyze and compare the financial consequences of a "department-only" PACS with a "whole-hospital" PACS utilizing the same basic assumptions. A departmental PACS potentially would allow the possibility of a phased introduction of PACS. This approach has been adopted in nearly all the early PACS installations and has enabled the requirements and specification of the elements of PACS installations to be developed and refined. As a result of the installation of these early systems, and of the rapid growth in technology, obtaining the benefits of whole hospital installations is now a realistic possibility. An economic analysis of whole hospital and departmental systems is described below.

\section{ANALYSIS BASED ON "ZERO" INFLATION}

The analysis is based on zero inflation model and a discount rate of $6 \%$. The value of inflationrelated elements that are expected to be greater or less than the present inflation rate are included as differences above or below the present inflation rate.

\section{ASSUMPTIONS}

An annual increase in workload of $2 \%$ is assumed. This is reflected in an increase in film

From the North West Thames Regional Health Authority London, England.

Address reprint requests to $H$. I. Glass, MD, North West Regional Health Authority, 40 Eastbourne Terrace, London W2, England.

Copyright (C) 1991 by W.B. Saunders Company

0897-1889/91/0404-0111803.00/0 
costs and storage space requirements and is superimposed on the film costs. Labor costs are assumed to be in line with inflation, except in the case of professional groups (clinicians and radiographers) whose salaries are assumed to be $1 \%$ above inflation. It is assumed that the cost of equipment maintenance will increase in line with the rate of inflation. The cost of building and space is assumed to be $5 \%$ above the inflation rate. This factor is applied to the opportunity space created by the virtual abolition of the requirement of space for a film store.

\section{DIRECT COSTS/SAVINGS}

\section{Capital}

The capital cost has three elements, namely $\mathrm{x}$ ray diagnostic equipment, building costs and adaptations, and PACS components (workstations, networks, image and data management systems and interfaces). The main difference relates to the additional cost of the PACS equipment and the reduced requirement for film processors. One processor should be retained for backup purposes. A $10 \%$ contingency sum should be incorporated to allow for continuing developments and equipment variations.

\section{Labor}

The improvement in professional and clerical efficiency which will be possible as a result of the introduction of PACS arises from elimination of film processing, filing, and handling and will allow significant savings in labor costs. These improvements will be possible not only in the radiography department but throughout the hospital, where a substantial time of a significant number of clerical staff in wards and clinics is spent organizing and handling films and film envelopes.

\section{Archive Materials}

The use of film would virtually cease, and images would probably be stored on optical disks. The cost of optical disks is decreasing rapidly, and the total cost of optical storage will be dependent to some extent on the use and acceptability of high-ratio nonreversible data compression algorithms. It has been assumed that such algorithms will be used. At present, confirmation of the clinical acceptability of this technique is being studied at various institutions, and current findings are very encouraging. There are some outstanding legal uncertainties concerning use of nonreversible compression. There is a requirement to store $\mathrm{x}$-ray images for 8 years and it has been assumed that the storage requirements will increase by the rate of increase in workload.

\section{Space}

The effective elimination of the film library will result in the availability of one eighth of the present space (approximately 50 square meters) each year for the 8 years after implementation of the system.

\section{Operational Costs}

Numerous routine operational costs are associated with the radiography department. One major expense is that associated with purchase of large film envelopes and associated stationery and filing and storage furniture. Allowance has been made in the model for savings arising because these items are no longer required after PACS is implemented.

\section{Maintenance}

One of the major additional expenses incurred with the introduction of PACS is the maintenance costs associated with the computerized digital equipment. This equipment is currently very reliable, and a maintenance cost of $5 \%$ of the equipment cost has been assumed. The economic viability of the project is sensitive to this factor.

\section{INDIRECT COSTS/SAVINGS}

All the factors discussed above are direct costs or savings since they can be controlled directly by managerial action and are attributable to specific costs headings. In the cases discussed below it is anticipated that savings can be made by more effective utilization of staff time, by avoidance of unnecessary investigations, by redesignation of acute beds and by reduction in length of hospital stay.

\section{Unnecessary Investigations}

It is assumed that unnecessary investigations or repeated examinations account for $10 \%$ of all investigations, and that they would be avoided by the immediate availability of the results of other imaging investigations on the same patient, even those just completed on another imaging 
Table 1. Comparison of Department and Hospital PACS: Accumulated Costs/Savings Over 10 Years (SM) Assuming Zero Inflation

\begin{tabular}{lcc}
\hline & $\begin{array}{c}\text { Whole } \\
\text { Hospital } \\
\text { System }\end{array}$ & $\begin{array}{c}\text { Department-Only } \\
\text { System }\end{array}$ \\
\hline Direct costs/savings & & \\
$\quad$ Archive/film materials & -2.00 & +3.35 \\
Labor & -0.80 & +0.25 \\
Operations & -0.25 & +0.35 \\
Space savings & -1.35 & +0.05 \\
Capital expenditure & +9.74 & +5.61 \\
Maintenance & +4.05 & +2.35 \\
Subtotal & +9.95 & +11.96 \\
Indirect savings & & \\
Junior medical staff time & -1.55 & 0.0 \\
Radiologist time & -1.10 & -1.10 \\
Radiographer time & -1.25 & 0.0 \\
Medical staff time & -2.70 & 0.0 \\
Hospital clerks & -1.25 & 0.0 \\
Unnecessary investigations & -2.30 & -2.30 \\
Reduced length of stay & -3.20 & 0.0 \\
Redesignation of acute beds & -1.90 & -1.90 \\
Subtotal & -15.25 & -5.30 \\
Net total & -5.30 & +6.66 \\
Net present value & -2.01 & +5.58 \\
Equivalent annual cost & -0.215 & +0.596 \\
\hline
\end{tabular}

device. Savings due to this element has been estimated at approximately $8.5 \%$ of the total departmental costs because all components contributing to departmental costs are involved.

\section{Junior Medical Staff}

It is estimated that the whole time equivalent of five junior medical staff is used in searching for and preparing films for the large number of joint $\mathrm{x}$-ray conferences held in the hospital.

\section{Radiology and Radiography Staff}

The substantial improvement in department efficiency will provide additional time for both radiologists and radiographers to enhance the utilization of the department's resources. This will allow enhanced "income generation" by the department. This saving has been expressed as an efficiency improvement and is conservatively estimated as a $15 \%$ saving of the labor costs of these two groups. It is anticipated that this estimate may be significantly understated, especially in the case of the radiologist.

\section{Medical Staff}

It is estimated that there will be a significant improvement in the efficiency of the medical staff resulting from the "instant" availability and ready access to radiographic images and reports. There will be substantial savings of medical staff time, which may allow enhanced income generation time. An estimate of $2 \%$ increase in efficiency has been converted to a comparable "saving" in the labor component of the medical staff cost. This is considered likely to be a very conservative estimate of the real cost benefit.

\section{Hospital Clerical Staff}

It is estimated that there will be an improvement in efficiency of the clerical staff serving the wards and outpatient clinics on the order of $25 \%$ because they will no longer be required to spend any time in handling $\mathrm{x}$-ray envelopes.

\section{Redesignation of Beds}

At any time, a significant number of acute beds are occupied by patients undergoing radiological investigations and requiring minimal nursing care. These patients could be accommodated in "5-day" beds.

\section{Reduction in Length of Stay}

If a minimal reduction in length of stay were achieved by the reexamination of operational procedures resulting from introduction of a filmless hospital, it would be equivalent to a significant reduction in cost of hospital operation that has been conservatively estimated at $0.5 \%$ of the hospital operations cost.

\section{RESULTS OF APPLICATION OF THE MODEL}

\section{Department-Only System}

The results of the department-only study assume that there would be no savings due to archive materials, since film must still be used. Labor savings would be significantly reduced because filing clerks and hospital clerical staff must be retained and will continue to spend a significant time handling film.

Capital cost and maintenance cost would be reduced. There would be no operational cost savings because the film library must still be retained and no film store space will be saved. There would be no cost savings in medical and radiographer staff time, and any reduction in length of stay is unlikely since there would be no rapid availability of images in the hospital. The inability to make these savings results in an NPV which 
is never negative; thus, the department-only option is not justifiable economically, given the present assumptions that the National Health Service will finance arrangements. The NPV and equivalent annual costs are shown in Table 1 for the hospital and department-only systems.

\section{Hospital System}

The total direct and indirect costs/savings for each of the main headings discussed above are summarized in Table 1 . The system is assumed to have a lifetime of 10 years from inception. The NPV goes negative after 9 years from the start of the project, indicating a NPV of $-\$ 0.34$ million after 10 years. The contribution of the indirect savings is an essential factor in achieving a justifiable investment decision. The equivalent annual cost of the hospital-based system after 10 years is a saving of $\$ 37,000$ per year. Many of the assumptions in the model are very conservative.

\section{DISCUSSION}

The economic analysis of the hospital PACS installation is based on a conservative but realistic model. The results derived from the model depend on the reliability of the assumptions and

Table 2. Identification of Qualitative Benefits

Patients benefits of PACS
Reduced waiting time for radiography department
investigation
Reduced waiting time in the radiography department
Reduced waiting time for results of investigations
Reduced waiting time before follow-up action
Reduced radiation dose to patient
Improved accuracy of diagnosis
Hospital benefits of PACS
Rapid access to current and archived image diagnostic
information when required in clinics, wards, and theaters
No loss of images or image reports
Improved efficiency of outpatient clinics and wards
Enhanced scope and range of efficiency of teaching activities
Improved efficiency of operation of the hospital and
radiography department

Table 3. Assessment of Attributes

\begin{tabular}{lccc}
\hline \multicolumn{1}{c}{ Attribute } & Weight & $\begin{array}{c}\text { Conventional } \\
\text { Department }\end{array}$ & $\begin{array}{c}\text { Filmless } \\
\text { Hospital }\end{array}$ \\
\hline Benefits to patients & 15 & 5 & 7 \\
Convenience to patients & 15 & 5 & 7 \\
Patient throughput & 10 & 5 & 8 \\
Reliability & 15 & 10 & 9 \\
Access to information & 9 & 4 & 10 \\
Loss of information & 5 & 4 & 10 \\
Convenience to staff & 7 & 6 & 8 \\
Acceptability to staff & 7 & 8 & 5 \\
Ease of operation & 7 & 10 & 8 \\
Appropriate utilization of staff & 5 & 4 & 10 \\
Teaching and research & 5 & 3 & 10 \\
Weighted scores & 100 & 609 & 812 \\
\hline
\end{tabular}

the ability of management to implement the operational changes to ensure achievement of the indirect benefits. A conservative attitude has been maintained in all of the assumptions of the model, except perhaps in relation to maintenance costs, where the maintenance cost expressed as a proposed percentage of capital cost is considered achievable. The qualitative benefits are shown in Table 2. Table 3 assesses the attributes of the effects of PACS, with suggested weighting factors, indicating the higher "score" achieved by a filmless hospital over a conventional hospital.

Because the capital cost is incurred early in the implementation process, any reduction in cost of the equipment crucially affects the economics of the project. As the technology continues to improve, especially in workstation cost and performance, the capital cost of the digital equipment may be reduced. Significant cost reductions can be expected if PACS installations are implemented in many locations, which in turn will depend on an early demonstration at key sites of its economic viability.

What emerges clearly from our study is that it is very unlikely that PACS could be economically justified purely on the basis of direct cost savings. The continuing benefits in quality of service to patients and qualitative improvement in the imaging service indicate that investment in PACS is worthy of serious consideration. 